\title{
Translating humour in audiovisual media ${ }^{1}$
}

\author{
Peter Zolczer \\ Department of Modern Philology, J. Selye University, Komárno, Slovakia \\ zolczer.peter@selyeuni.sk
}

\begin{abstract}
The article investigates humour translation in audiovisual media concentrating on two modes of audiovisual translation: dubbing and subtitling. The corpus consists of humorous scenes collected from two popular American situational comedies, namely Friends (1994) and The Big Bang Theory (2007). The analysis is based on the comparison of the humorous scenes in their original (English) audio track with their dubbed and subtitled Hungarian versions. Only those humorous scenes were selected and analysed in which the humorous load is mediated by language- and/or culture-specific humorous elements. The study focuses on the differences between the scenes' humorous load in their original, dubbed, and subtitled versions. The methodology of the research is based on Juan José Martinez-Sierra's case study "Translating Audiovisual Humour" (2009). The results show that in certain cases there is a difference between the humorous load in the dubbed and subtitled versions which can be traced back to the differences between the constraints of dubbing and subtitling.
\end{abstract}

Keywords: humour, translation, audiovisual, dubbing, subtitling.

\section{Introduction}

Audiovisual translation is a relatively recent field of research; it dates back to the late 1950s and early 1960s. According to Díaz Cintas the beginnings of the field have been "sluggish and shaky", but it began to get more and more attention at the close of the $20^{\text {th }}$ century (Díaz Cintas 2009: 1). As pointed out by many researchers (Cho 2014; Díaz Cintas 2003; Chiaro 2009; Fois 2012) until the recent years there has been a confusion about the definition and terminology of the field. TV translation, film translation, media translation, screen translation; various terms have been used interchangeably. However, recently scholars of the field seem to have agreed on using the term audiovisual translation. AVT is defined as "the interlingual transfer of verbal language when it is transmitted and accessed both visually and acoustically, usually but not necessarily, through some kind of electronic device" (Chiaro 2009: 141). We differentiate various modes of AVT, such as dubbing, subtitling, voice over, narration, or surtitling. The 
number of modes varies according to the classification we use. For instance Bartolomé and Cabrera (2005) differentiate as many as 17 audiovisual translation modes. This article investigates two of these modes: subtitling (the addition of the translation of the audio output in verbally coded messages to the original video track) and dubbing (the replacement of the original audio output with the translated audio output).

No one would deny the fact that translating humour is not easy. There are some cases, however, when it is especially difficult. In these cases the humorous load is conveyed by linguistic elements that are unique to the language in question (e.g. wordplays, idioms). In order to maintain the humorous load of this kind of humour a high level of creativity is required from the translator. When the language element - creating or contributing to the humorous load - of the source language does not have an equivalent in the target language, the translator is usually forced to reduce or completely leave out the humorous load. The amount of this reduction is usually limited "only" by the differences in the source and target language and culture. In the cases of dubbing and subtitling (and also in the case of many other modes of AVT), these restrictions (limitations) are extended with the inherent constrains of these modes of AVT. Bartrina and Espasa claim that the activity of translation involving such constraints are "[...] situations where the text to be translated is part of a more complex communicative event which attempts to convey a message by various means, such as pictures, drawings, music, etc." (Bartrina \& Espasa 2005: 83). This article is an attempt to compare and analyse humorous scenes of audiovisual media in English-Hungarian language pair in order to reveal the characteristics of translating humour for dubbing and subtitling.

\section{Theoretical framework}

The theoretical background used in this analysis is based on Martínez-Sierra's case study "Translating Audiovisual Humour" (2009). The aims of his study were (1) to create a method for analysing humour, (2) to describe the way humour is translated, and (3) to recognise tendencies related to humour translation. All of his objectives were stated in the context of AVT. His corpus consisted of certain episodes of the popular animated TV comedy The Simpsons. Martínez-Sierra conducted a qualitative and quantitative analysis based on 365 humorous instances collected from four episodes of The Simpsons, focusing mainly on the original English and the dubbed Spanish versions. To be able to be as objective as possible he created an ad hoc taxonomy of humorous elements:

(1) Community-and-Institutions Elements, meaning culture-specific items (celebrities, politicians, films, books, etc.).

(2) Community-Sense-of-Humour Elements relate to topics which are more well-known in certain communities, but are not culture-specific.

(3) Linguistic Elements.

(4) Visual Elements are those which produce or contribute to the humorous load by way of what we see on the screen, excluding the visually coded versions of linguistic elements.

(5) Graphic Elements are the humorous written messages on the screen.

(6) Paralinguistic Elements are the non-verbal elements of a voice (rhythm, resonance, tone, intonation, timbre).

(7) Non-Marked (Humorous) Elements are miscellaneous examples contributing to the humorous load which cannot be categorised. 
(8) Sound Elements are sounds or combinations of sounds which can convey a humorous load.

This taxonomy is of a great use, since it allows the identification of change or loss in the humorous load of any humorous scene. In order to make the analysis clear and systematic, Martínez-Sierra created tables (cards) which contained all the necessary information about the humorous scenes (the season and episode number, the original and the target transcription, context, load difference, comments). His results show (among others) the following tendencies of translating humour in the context of AVT:

a) Most humour (in the analysed corpus) is translatable.

b) The shared background knowledge of the audience plays an essential role in translating humour in AVT.

c) Translating humour in AVT demands the rendering of humorous elements which interact in unique ways.

The intention of using a taxonomy of humorous elements in this article was to reduce the subjective aspect of determining the humorous load of the analysed scenes as much as possible. The tendencies also provided a valuable basis for the qualitative analysis of the scenes in question.

\subsection{Dubbing}

Understanding the analysis of the humorous situations described in this article requires the introduction of the basic features of dubbing as a mode of AVT, and also the constraints it creates in the process of translation. According to Luyken et al. (1991: 31), dubbing is "the replacement of the original speech by a voice track which attempts to follow as closely as possible the timing, phrasing and lip-movements of the original dialogue". The advantages (e.g. availability to larger audiences, no need for reading subtitles) and disadvantages (e.g. timeconsuming and expensive, authenticity and credibility issues) of dubbing are often discussed among the researchers of the field. Nevertheless, a tendency seems to emerge from the various opinions, which is brilliantly summarised by Chiaro in a single sentence: "It would not be unfair to say that dubbing has a worse reputation in subtitling countries than subtitling has in dubbing countries" (Chiaro 2009: 147). The process of dubbing involves numerous steps. How these steps restrict the translator can easily be seen by considering those factors which need to be synchronised:

(1) Lip movements in shots where the lips or the whole face of the actors are visible - the target text (utterance) must coincide with the actor's lip movements, mainly in the cases of bilabial and labio-dental consonants and open vowels.

(2) The body movements of the actors - the target text (utterance) must coincide with the actor's head, arm, or any other body movement, which usually occurs in cases of assertion, negation, surprise, etc.

(3) The timing of the actors' utterances - the target text (utterance) must coincide with the time interval which starts with the character opening his/her mouth and ends with closing it. 
Chaume Varela proposed the following definition, which encompasses all three factors: "Synchronization is one of the features of translation for dubbing, which consists of matching the target language translation and the articulatory and body movements of the screen actors and actresses, as well as matching the utterances and pauses in the translation and those of the source text" (Chaume Varela 2004: 43). This article uses Chaume Varela's definition, since by including all three factors (phonetic, kinetic, isochronic) it serves as an effective tool for identifying the characteristics of humour translation in AVT.

\subsection{Subtitling}

Gottlieb defines subtitling as "the rendering in a different language of verbal messages in filmic media, in the shape of one or more lines of written text presented on the screen in sync with the original written message" (Gottlieb 2001: 87). An important factor of subtitling is that subtitles are always compressed versions of what can be heard on the audio track of the audiovisual media. This means that even if the subtitles are in the same language as the original audio, they will not be the same as the transcription of the characters' utterances. It is necessary for the subtitles to be shorter than the audio, because it is essential for the viewer to have enough time to read them, even during a fast dialogue. In an ideal case the viewer can read the captions with such a minimal effort that he or she does not even notice the process of reading. According to Antonini, the reduction of the utterances regarding the number of words they include varies between 40 to 75 (!) per cent (Antonini 2005: 213). He defines three procedures which are required from the translator in order to produce effective subtitles:

(1) Elimination - the process of cutting out elements from the transcription of the audio which do not distort or modify the meaning of original.

(2) Rendering - the process of dealing with dialects, taboo/bad language, or slang.

(3) Simplification - the process of promoting comfortable reading by fragmenting and simplifying the syntax of the original (Antonini 2005: 213-214).

From a translational point of view, there is one technical constraint which can cause difficulties for the translator; the maximum number of characters to be visualised on screen is usually 30 to 40, positioned into one or two lines (Gottlieb 2001). Another technical constraint which in certain cases might cause further complications for the translator and is closely connected to the process of simplification is the exposure time for each subtitle which is 3-5 seconds for one line and 4-6 for two lines (Linde \& Kay 1999: 7). All conventions of subtitling are generally accepted in countries where they use this mode of AVT, regardless of the differences in languages, which also can cause numerous difficulties for the translator. Compared to dubbing, subtitling seems to have more advantages than disadvantages. No distortion in the source language and the presence of the original audio belong to the former category, while the need for the additional reading belongs to the latter (Chiaro 2009: 150-151).

\section{Corpus and method}

The corpus consists of 25 humorous scenes from different episodes of the popular American television series Friends and The Big Bang Theory. The selection of the seasons and episodes was not based on any pattern. The main reason of selecting these particular series is that they are 
very popular ones in the genre of situational comedy, which makes them an ideal source of investigating humorous elements in AVT. The low number of humorous scenes analysed in this study indicates that it was qualitative research. The reason for not involving quantitative research was the way how the selected humorous scenes were collected. All 25 scenes contain a humorous situation which is based on a particular feature of the source language and/or culture. Since there is no possible way for an automated search for such humorous scenes, finding them is time consuming; it requires watching the episodes one by one, focusing on language-specific humour (usually wordplays) and noting them down. The details of each humorous scene are summarised in headings, where the season and episode number, time interval of the dialogue, the transcription of the source and the target audio track, and the subtitles are indicated. This is followed by the analysis which consists of four parts:

(1) The first part contains the description of the context and the determination of the humorous load. The transcription of the source and target audio track does not contain the visual elements of the situation, which is why in most cases the context is essential to understanding the humorous load of the situation. The description of the context is always based on the original (English) version of the scene.

(2) The second part includes the analysis of the target texts, which in fact is an attempt to reverse-engineer and show the techniques used by the translator(s). In certain scenes alternative versions of the target text are suggested and discussed. The humorous load of the target text is determined here as well.

(3) The third part contains the comparison of the humorous load of the source and the target text of the dubbed version, which shows whether the humorous load in the target text remained, changed, or was lost.

(4) The fourth part contains the comparison of the humorous load of the source and the target text of the subtitled version, which in many cases differs from the one used in dubbing.

In cases where there is a shift in the humorous load (reduction or loss), an attempt has been made to explain it by pointing out the possible strategies used by the translator and the specifics of the AVT mode in question. The primary goal of this article is not the analysis of the humour in the humorous load of the collected scenes, but the determination of the specific techniques and problems of translating them. The type of humour present in the selected scenes is not investigated, however, in most cases the analysis reveals that the type of humour is wordplay.

\section{Analysis}

The scene in Table 1. contains an example for a situation where the lip movement of the character causes some constraints in conveying the humorous load between the original and the dubbed version. 
Table 1. Example of a constraint of dubbing.

Friends, season 9, episode 10 [00:11:20 >> 00:11:30].

a) English audio track:

Monica - What does she do there?

Chandler-Oh, she's regional vice president. She's just below me.

Monica - She did what?

Chandler-Be-low-me.

b) Hungarian dubbing:

Monica - Na és mit csinál ott? [And what does she do there?]

Chandler - Hát ö a körzeti elnökhelyettes. Éppen alattam van. [Oh, she is the regional vice president. She is just below me.]

Monica - Hogy épp hol van? [Where is she?]

Chandler-A-lat-tam. [Be-low-me]

c) Hungarian subtitles:

The same as the dubbing.

Context: Chandler is talking with Monica (his wife) on the phone. There is a woman with Chandler in his office. Monica asks Chandler about the woman's job position.

Humorous load:

\begin{tabular}{|l|l|}
\hline English audio track: & $\begin{array}{l}\text { Hungarian dubbing: } \\
\text { Community-Sense }\end{array}$ \\
\hline Community-Sense + Linguistic. & \\
\hline Hungarian subtitles: & \\
Community-Sense & \\
\hline
\end{tabular}

The humorous load of this situation is generated by Monica's mishearing the word 'below' during the phone call. This becomes clear to the audience in her sudden reaction of asking Chandler what the woman did. Instead of "she's just below me", she heard 'she's just blown me', which is an informal way of expressing that 'she has just orally satisfied me'. The linguistic element in the humorous load consists of not just the lexical similarity and the usage of the words 'below' and 'blow'. The abbreviated 'she's' can be interpreted as 'she is' and 'she has' as well. If Chandler had not used the abbreviated form, Monica would not have misheard his sentence, since it would not have made sense ('She is just blown below me'). Because of the difference in the linguistic systems of the source and the target language, the Hungarian version does not contain any humorous load generated by a linguistic element. Also Monica's reaction "Hogy épp hol van?" [Where is she?] does not coincide with the original version. The community-sense-of-humour element is only partially maintained, because the Hungarian word 'alattam' [below/under me] in an informal conversation might have the meaning of 'the position of a person during an intercourse', but in this context it is not obvious. It is possible, however, to use another word instead of the second 'alattam' in order to fully maintain the humorous load of the community-sense-of-humour element. The word is 'beosztottam' [my employee], which would definitely inform the Hungarian audience that Monica misinterpreted Chandler's answer, and it would fully release the incongruity as well, generating humorous load as a result. The fact that the last syllable of the two words 'alattam' and 'beosztottam' is the same ('tam') would also 
partially convey the linguistic element of the humorous load of the original version. The reason why the translator(s) did not use this obvious solution is very simple: it would not have been possible to synchronise the word 'beosztottam' with Chandler's lip movement. As it is clear from the transcription of the dialogue, Chandler is intensely articulating the second 'below' ("below-me") in his final line with three distinct syllables. The suggested Hungarian version would consist of four different syllables (be-osz-tot-tam) which would make it impossible to synchronise it with Chandler's lip movements. The above scene is a perfect example of how dubbing can cause constraints in translating humour.

The next scene contains a situation where the loss of the humorous load is caused by a constraint that is emergent because of a specific graphic element.

Table 2. Example of a graphic element.

Friends, season 8, episode 13 [00:20:35 >> 00:20:45].

a) English audio track:

Joey - All that worrying I was doing? That was crazy. Crazy. Like my friend the bird here would say, "It was cuckoo!"

b) Hungarian dubbing:

Joey - Ezért izgattam magam. Ez hülyeség. Hülyeség. Ahogy madár barátom mondaná „Kakukk”. [This is why I was worrying. This is stupid. Stupid. Like my friend the bird would say, "Cuckoo!']

c) Hungarian subtitles:

The same as the dubbing.

Context: Joey is eating breakfast while he is thinking about his feelings towards Rachel. He is trying to convince himself that worrying about loving Rachel (one of his best friends) is completely unnecessary. There is a cereal box on the table with a bird and the label "Cocoa Puffs" on it.

Humorous load:

\begin{tabular}{|l|l|}
\hline English audio track: & Hungarian dubbing: \\
Graphic + Community-Institutions & None \\
\hline Hungarian subtitles: & \\
None & \\
\hline
\end{tabular}

The humorous load in this scene is generated by a culture-specific item, which is Sonny the Cuckoo Bird. The bird is a trademark for the cereals Cocoa Puffs. While Joey is talking about how he should not have worried about his feelings towards Rachel, reflecting back on his previous days, he refers to Sonny the Cuckoo Bird's slogan "I'm cuckoo for Cocoa Puffs!". Thus the humorous load consists of a community-and-institutions element which is a direct reference to a culture-specific item. However, Joey never mentions the name of the bird (Sonny), because the reference is created by the cereal box on the table visible for the audience. According to the taxonomy of humorous elements, the label "Cocoa Puffs" on the cereal box is a graphic element which is essential to notice in order for the humorous load to be conveyed as intended. Without it, the viewer would not realise the reference to the culture-specific item: Sonny the Cuckoo Bird. In the Hungarian version the word 'crazy' is translated as 'hülyeség' ['stupidity'], a word with a different semantic meaning, and for the word 'cuckoo' the translator uses its Hungarian 
equivalent 'kakukk'. The problem is that in Hungarian there is no linguistic connection (no converging mental representations) between the words 'kakukk' and 'örült' [crazy] or 'hülye' [stupid]. The graphic element is also "missing" from the target version, because the Hungarian audience is not encouraged to notice the label "Cocoa Puffs" on the cereal box (the Hungarian equivalent of 'cocoa' is 'kakaó'). The lack of the community-and-institutions and graphic elements in the Hungarian versions leads to the complete loss of the humorous load. The problem is that it is impossible to convey the same humorous load in the target version, because the key graphic element (the cereal box label in the video) cannot be changed. Therefore, the above scene is an example of a situation where the constraint for humour translation is created by a graphic element.

Note, however, that in this particular case, there is an alternative solution which would convey a non-marked humorous element in the subtitles. Since there is no way of telling the species of the bird on the cereal box, in the Hungarian version Joey might have said: "Papagáj barátom úgy mondaná „Lökött, lökött” [Like my friend the parrot would say, "Dumb, dumb”].

The following example contains a humorous load which is conveyed by the combination of a linguistic and a visual element. It clearly shows the difference between a graphic and a visual element and also between the translation of these elements.

Table 3. The first example of a visual element.

The Big Bang Theory, season 6, episode 5 [00:16:06 >> 00:16:11].

a) English audio track:

Bernadette - Uh-oh, is someone a little blue?

b) Hungarian dubbing:

Bernadett-O-ó. Mi törpént, törpikém? [Uh-oh. What happened, my little smurf?]

c) Hungarian subtitles:

Bernadett - Hüha, kezdesz elkékülni. [Uh-oh. You are getting blue.]

Context: Both Howard and Bernadette have their Smurfs costumes on, and their bodies are painted blue (they want to go to a costume party). Howard is feeling sad. Bernadette tries to cheer him up.

Humorous load:

\begin{tabular}{|l|l|}
\hline English audio track: & Hungarian dubbing: \\
Linguistic + Visual & Linguistic + Visual \\
\hline $\begin{array}{l}\text { Hungarian subtitles: } \\
\text { Visual }\end{array}$ \\
\hline
\end{tabular}

The visual element of the humorous scene in Table 3. is that both actors are painted blue to resemble the Smurfs as authentically as possible. Since Howard is sitting on the bed, watching his toes, clearly feeling sad, Bernadette's reference to his colour creates a connection with the idiom 'feeling blue', which causes a humorous effect. The idiom here is the linguistic element of the humorous load. In Hungarian, there is no idiom which would refer both to the colour blue and feeling sad. However, in both Hungarian dubbing and subtitles the humorous load remains the same. What makes this scene special is that despite the fact that the humorous load is present in the dubbed version, both the linguistic and the visual elements are different. In the Hungarian version, the reference which causes the humorous effect is not made to the colour blue, but to the 
actors being Smurfs (because they have the Smurfs costumes on). The word 'törp' in Hungarian means 'smurf' in English. The linguistic element is also present not because of an idiom, but because of a rhyme caused by a slight modification of the Hungarian word 'történni' ['to happen'] to 'törpénni' (a non-existent word), which makes it similar to the word 'törp'. The subtitles in this scene are different from the dubbing. Only the visual element is maintained in them, however, a different one than in the dubbing. In the subtitles Bernadette is referring to Howard's blue colour by saying that Howard is "getting blue" ("kezdesz elkékülni"). The connotations of this collocation might evoke a mental image of a person suffocating with his or her lips turning blue or being very cold, producing the same symptoms. The point is that in both cases the person is in a very uncomfortable situation. Howard, metaphorically, is also in a similar situation, which makes the Hungarian subtitles convey a humorous visual element. This scene shows that, contrary to a graphic element, it is possible to convey a visual element because the translator can refer to any of the aspects of it, in this case both the colour and the costumes of the artists.

The next scene contains an example of a case where the humorous load is entirely lost in the Hungarian dubbing, but is conveyed in the subtitles.

Table 4. The second example of a visual element.

Friends, season 4, episode 8 [00:18:00 >> 00:18:10].

a) English audio track:

Timothy - You have very beautiful ... eye.

b) Hungarian dubbing:

Timothy - Neked fantasztikusan szép a ... szemed. [You have a very beautiful ... eye]

c) Hungarian subtitles:

Timothy - Neked fantasztikusan szép a ... fél szemed. [You have very beautiful ... half an eye]

Context: Timothy wants to compliment on Monica's eyes. Monica has an eye patch on one of her eyes.

Humorous load:

English audio track:

Linguistic + Visual

Hungarian dubbing:

Hungarian subtitles:

None

Linguistic + Visual

In Table 4., the humorous load contains a linguistic and a visual element. The visual element consists of Monica having an eye patch on one of her eyes. The other character, Timothy, wants to compliment on Monica's eyes and only realises that she has the eye patch in the last half of his sentence ("You have very beautiful ... eye."). The eye patch prevents Timothy from referring to both of Monica's eyes, which is why he uses the singular form of the word 'eye'. This slight modification in the collocation provides the linguistic element in the humorous load of this scene. The Hungarian dubbing loses the humorous load, because in Hungarian we refer to the eyes of someone in singular ('szemed' [your eye] and not 'szemeid' [your eyes]) (Klaudy 1999: 55). This might even cause confusion in the Hungarian viewer, because the reason for the laugh track (the background laugh typical in sitcoms) is not obvious. The subtitles, however, do convey 
the humorous load by adding an extra word before 'szemed', which is the word 'fél' [half]. In Hungarian, when we refer to a single body part, we usually use this word (e.g. 'féllábú kalóz' [one-legged pirate]). The reason why this solution could not have been used in dubbing is the fact that the word 'eye' is monosyllabic and the phrase 'fél szemed' contains three syllables. The lip movement synchronisation constraint would not allow two extra syllables in the Hungarian dubbing. This scene is an example of a situation where the humorous load could only have been conveyed in the subtitles, but not in dubbing.

The following humorous scene is an example of differences between the Hungarian dubbing and subtitling where the humorous load in the case of dubbing is conveyed but at the same time converted.

Table 5. Example of the change of the type of humorous element.

Friends, season 9, episode 23 [00:02:40 >> 00:02:50].

a) English audio track:

Ross - Dear Sarah. I dig you. Dr. Ross Geller.

b) Hungarian dubbing:

Ross - Kedves Sarah-nak. Sok dínóval. Dr. Ross Geller. [Dear Sarah. With lots of dinosaurs.]

c) Hungarian subtitles:

Ross - Drága Sarah. Maga egy csinos kis lelet. Dr. Ross Geller. [Dear Sarah. You are a nice little fossil.]

Context: On a conference organised for paleontologists, a fan wants to ask for an autograph from Ross (who is a paleontologist himself).

Humorous load:

\begin{tabular}{|l|l|}
\hline $\begin{array}{l}\text { English audio track: } \\
\text { Community-Institutions + Community- } \\
\text { Sense }\end{array}$ & $\begin{array}{l}\text { Hungarian dubbing: } \\
\text { Community-Sense + Linguistic }\end{array}$ \\
\hline $\begin{array}{l}\text { Hungarian subtitles: } \\
\text { Community-Sense + Community-Institutions }\end{array}$ \\
\hline
\end{tabular}

The humorous load in the example above is generated by two elements: community-andinstitutions and community-sense-of-humour. The community-and-institutions element is created by the use of the slang phrase 'I dig you' which means 'I really like you'. The word 'dig' in this context (paleontological conference) has an extra meaning ('digging up fossils') which in turn provides a community-sense-of-humour element only the community of paleontologists can fully appreciate. With regard to Hungarian dubbing, despite present, the community-sense-of-humour element is modified and the community-and-institutions element is exchanged with a linguistic one. The phrase "Sok dínóval" [with lots of dinosaurs] is the altered version of 'sok szeretettel' [with lots of love] where the word 'dínó' [dinosaur] replaces the word 'dig' to maintain the community-sense-of-humour element. 'Sok szeretettel' [with lots of love] in Hungarian is a commonly used phrase for ending letters, especially postcards and is also used for ending autographs. This is the way the linguistic element is created in the phrase "Sok dínóval". In the Hungarian subtitles, however, both humorous elements of the original utterance are maintained. "Maga egy csinos kis lelet" [You are a nice little fossil] contains the word 'lelet' [fossil] to 
convey the community-sense-of-humour and the phrase 'maga egy csinos kis...' which combined with the word 'lelet' [fossil] mediates the community-and-institutions element, since in this context it functions as slang. Although the humorous load of the utterance in the subtitles is closer to the original than the one in the dubbing, the lip movement constraints do not allow it to be used in the latter. This example shows that despite the constraints of dubbing, by modifying the elements of the humorous load of the original utterance, it is possible to convey the humour. It also shows that the constraints of subtitles allow more flexibility than the constraints of dubbing.

The scene in Table 6. contains a situation where the inevitable loss of one of the humorous elements is compensated by using a different semantic meaning of the same element. The constraint of translating this particular humorous situation does not derive from the features of dubbing; however, it includes an interesting translational solution which might be useful in situations where the translator is restricted because of the lip movements of the characters. 
Table 6. Example of the compensation for the loss of a humorous element.

Friends, season 9, episode 3 [00:10:10 >> 00:10:35].

a) English audio track:

Monica - What are you doing?

Chandler-Looking for restaurant jobs for you in Tulsa.

Monica - Aw, that's so sweet. Did you find anything?

Chandler-Slim Pickins.

Monica-Hmm. Nothing, huh?

Chandler - No. Slim Pickins. It's a barbecue joint.

$\cdots$

Monica - "Slim Pickins"? That is so cheesy.

Chandler - Well, So Cheesy also has an opening.

b) Hungarian dubbing:

Monica - Mit csinálsz? [What are you doing?] Tulsa.]

Chandler - Hát... Állást keresek neked Tulsában. [I'm looking for jobs for you in

Monica - Oh, de cuki vagy. Találtál valamit? [Aw, you're so sweet. Did you find anything?]

Chandler - Sovány moslék. [Light Pigswill]

Monica - Hmm. Szóval semmi? [Hmm. So nothing, right?]

Chandler - Nem. A Sovány moslék egy barbecue-büfé. [No. Light Pigswill is a barbeque joint.]

$\cdots$

Monica - "Sovány moslék"? Fincsi hely lehet. ["Light Pigswill”? It must be a delicious place.]

Chandler-Nem. A Fincsi az most nyilik. [No. Delicious has an opening now.]

c) Hungarian subtitles:

The same as the dubbing.

Context: Chandler is sitting at the table looking at his laptop. Monica arrives home and the dialogue starts.

Humorous load:

\begin{tabular}{|l|l|}
\hline English audio track: & Hungarian dubbing: \\
Community-Institutions + Linguistic & Linguistic + Non-Marked \\
\hline Hungarian subtitles: & \\
Linguistic + Non-Marked & \\
\hline
\end{tabular}

The humorous load in the scene above is generated by the combination of a community-andinstitutions and a linguistic element. The former contains the idiomatic meaning of 'slim pickins' and 'cheesy' while the latter is realised by using these two phrases as names for restaurants. The first time Chandler uses the phrase 'slim pickins', it is his answer to Monica's question about job offers in Tulsa. 'Slim pickin(g)s' has the idiomatic meaning of 'very few, almost no choices'. Because of the context, Monica interprets Chandler's answer as 'basically no jobs in Tulsa'. 
Chandler then tells her that "Slim Pickins" is actually the name of a restaurant which has a job offer. Monica then characterises the selection of "Slim Pickins" as a name for a restaurant as "so cheesy" (the phrase 'so cheesy' also has an idiomatic meaning of 'inauthentic'). Then Chandler tells Monica that "So Cheesy" is the name of another restaurant (probably meaning 'so cheeselike' or 'so tasty'). The humorous load is generated by Monica's using the idiomatic and Chandler's using the lexical meanings of the phrases. In the Hungarian version "Slim Pickins" is translated as "Sovány moslék" [Light Pigswill] which as a phrase does not have an idiomatic meaning; however, the constituent words 'sovány' [light] and 'moslék' [pigswill] do create a humorous load, since the purpose of pigswill is to fatten up the pig, hence a light version of pigswill would make no sense. "Cheesy" in the Hungarian version is translated as "fincsi" [delicious] and Monica uses it not to describe the name-selection of Slim Pickins, but to describe the restaurant itself. The humorous load in the Hungarian version is created by the conflicting associations of mental images which the words 'moslék' [pigswill] and 'fincsi' [delicious] evoke. This way the missing idiomatic meanings (community-and-institutions element) from the Hungarian version are compensated with the careful and creative selection of words (non-marked element). ${ }^{2}$

The next scene contains an example of the loss of the humorous load, which in the English version is generated by a linguistic element, specifically by using rhymes. 
Table 7. Example of the loss of a humorous element.

The Big Bang Theory, season 6, episode 5 [00:16:06 >> 00:16:11].

a) English audio track:

Amy-Professor Tupperman is dead. And that makes us?

Sheldon-Sad.

Amy - The fact that there are so many people here tonight doesn't make us cranky and claustrophobic. It makes us?

Sheldon-Glad.

Amy - Giving Mrs Davies the box set of Roots was?

Sheldon-Bad.

b) Hungarian dubbing:

Amy-Tupperman professzor meghalt és ez nekünk? [Professor Tupperman died. Now we feel?]

Sheldon-Fáj. [It hurts.]

Amy - Az, hogy ilyen sokan eljöttek, nem idegesitö és klausztrofób érzés, hanem nagyon? [The fact that so many people came doesn't make us cranky and claustrophobic. It makes us feel?]

Sheldon - Jó. [Good.]

Amy - Misiss Davies-nek Gyökerek DVD-t ajándékozni? [Giving Mrs Davies the Roots DVD was?]

Sheldon-Rossz. [Bad.]

c) Hungarian subtitles:

The same as the dubbing.

Context: Amy wants to rehearse the emotional responses of Sheldon (who is struggling with empathy) before going inside the hall where people gathered to honour the life and work of Professor Tupperman.

Humorous load:

\begin{tabular}{|l|l|}
\hline English audio track: & Hungarian dubbing: \\
Linguistic & None \\
\hline Hungarian subtitles: \\
None
\end{tabular}

The humorous load in this example is created by a simple a-a-a rhyme scheme with the words 'sad', 'glad' and 'bad'. In the Hungarian dubbing and subtitles there is a lack of rhyming words, since the three Hungarian words used are 'fáj' [it hurts], 'jó' [good], and 'rossz' [bad]. The reason for not using rhyming words in the dubbing might be due to one of its constraints, specifically, the lip movement synchronisation. All three English words are monosyllabic and in all cases the lip movement of the character is visible, which means that the Hungarian words must also be monosyllabic. The translator probably was not able to find three monosyllabic Hungarian rhyming words with similar meanings to fit in this context. However, the reason for not selecting three rhyming words for the subtitles is unknown. The subtitles do not require the words to be monosyllabic, so for example the words 'fájó' [it is aching], 'jó' [good], and 'nem jó' [not good] might have been used to convey the humorous load of the original utterance. 


\section{Results}

While the limited number of the analysed humorous scenes (25) does not allow us to form reliable generalisations, a summary of the changes in the humorous load of the scenes in the target language versions might be useful in forming hypotheses about the translation of humour in AVT, especially in two of its modes: dubbing and subtitling. The analysis showed that there are different situations which can serve as the basis for forming categories of the problems of humour translation in audiovisual media:

1) Constraints caused by the lip movement synchronisation - it is important to mention that in most of these cases the humorous load was lost or greatly reduced in dubbing while it was possible to convey the same humorous load in the subtitles.

2) Constraints caused by a graphic element (e.g. verbally coded message) - in these cases it was impossible to convey the humorous load in both dubbing and subtitling, since the video track could not be modified.

3) Constraints caused by a visual element - both in dubbing and subtitling it is much more likely for the humorous load to be conveyed because the target language audience can perceive the visual elements in the same way as the source language audience, since it is not verbally, but visually coded.

A fourth situation was also detected, but since it is rather a technique for dealing with possible problems of humour translation in AVT, I will mention it separately from the three aforementioned situations connected to the constraints of certain modes of AVT. In some cases the type of one or more humorous elements was changed because of the nature of the target language and/or the constraints of the mode of AVT, but at the same time the humorous load was conveyed. From a different perspective one can think of it as losing one or more humorous elements of the original utterance but also creating new ones (usually in the same number) in the target language.

The analysis also pointed out questions relating to methodology, of which the one connected to the degree of the humorous load is the most important. In this analysis the degree of the humorous load was determined by the number of humorous elements in it. The humorous load is conveyed (maintained), reduced, lost, or increased based on the comparison of the number of humorous elements in the original scene and its dubbed and subtitled versions (e.g. if the number of the humorous elements match, the humorous load is conveyed; if the number of the humorous elements in the dubbing is less than in the original version, the humorous load in the dubbing is reduced, etc.). However, even if the number of the humorous elements is the same, the type of the elements can differ (e.g. a linguistic humorous element becomes a non-marked element as in Table 6.), which makes it difficult to compare with the original, since different types of humorous elements might evoke different degrees of humorous effect. Another issue relates to the differences of the humorous load in dubbing and in subtitles, especially in countries where dubbing is preferred over subtitling. Even though this problem focuses on a special case, determining the humorous load in a certain scene for these audiences might not be a reliable way of analysing and comparing the humorous effect (e.g. while reading the subtitles the audience might miss the visual element of the scene because they are not used to reading subtitles). A connection might be drawn between this problem and the constraints of subtitling, specifically the minimal visibility time per subtitle. 


\section{Conclusion}

Translating humour often opposes the translator with problems rooted in the very nature of humour translation. Generally, these problems are caused by (1) differences in the source and target language and/or culture, and (2) the "untranslatability" of the language and/or culturespecific items. In the case of audiovisual translation, the number of problems is increased simply because of the characteristics of this type of translation. In the process of dubbing, even if the translator has a perfect translation for a humorous situation, he/she might not be able to apply it. Most of the times this happens because of lip movement synchronisation. Of course, this is true for non-humorous situations as well, however, in these cases the number of alternative options makes it less difficult to produce a usable translation (even in the case of dubbing there are more ways of translating a non-humorous utterance than a humorous one). In the case of subtitling, despite the great number of constraints (e.g. maximum number of characters to be displayed in one subtitle), it is more likely that the translator can find a usable translation of the original utterance while conveying the same amount of humorous load. This article deals with the analysis and comparison of humorous scenes in their original English and Hungarian dubbed and subtitled versions. The humorous scenes are collected from different episodes of two famous American television sitcoms, Friends and The Big Bang Theory. The results indicate a tendency for a number of different situations which might be used to form categories of problems of humour translation caused specifically by certain features of audiovisual translation (e.g. constraints of dubbing and subtitling). The analysis also pointed to a number of questions connected to the methodology used for analysing the humorous load in the humorous scenes. Considering these questions, improving the method for analysing humour in AVT, and expanding the corpus might strengthen the results of a similar analysis, and at the same time it might reveal previously unknown features of humour translation in audiovisual media.

\section{Notes}

${ }^{1}$ This article is an extended version of "The constraints of translating humor in audiovisual media" (Zolczer 2014), presenting new findings on the topic of humor translation in audiovisual media, especially considering translating humour with subtitles.

${ }^{2}$ In both dubbing and subtitles, the English sentence "Delicious has an opening now" is translated literally to "A Fincsi az most nyílik" [Delicious is opening at the moment (it is a new place)], thus ignoring the idiomatic meaning of 'to have an opening', which means to have a position for a job.

\section{References}

Antonini, R. (2005). 'The perception of subtitled humour in Italy: An empirical study', in Chiaro, D. (ed.), HUMOR: International Journal of Humor Research, Special Issue Humor and Translation, 18 (2), pp. 209-225.

Bartolomé, A. I. H. \& Cabrera, G. M. (2005). 'New trends in audiovisual translation: The latest challenging modes'. Miscelánea: A Journal of English and American Studies 31, pp. 89-104. 
Bartrina, F. \& Espasa, E. (2005). 'Audiovisual translation', in Tennent, M. (ed.), Training for the New Millennium. Pedagogies for Translation and Interpreting, Amsterdam/Philadelphia: John Benjamins Publishing Company, pp. 83-100.

Chaume Valera, F. (2004). 'Synchronization in dubbing: A translational approach', in Orero, P. (ed.), Topics in Audiovisual Translation, Amsterdam/Philadelphia: John Benjamins Publishing Company, pp. 35-52.

Chiaro, D. (2009). 'Issues in audiovisual translation', in Munday, J. (ed.), The Routledge Companion to Translation Studies, London and New York: Routledge, pp. 141-165.

Cho, S-E. (2014). Basic Concepts in the Theory of Audiovisual Translation. Hankuk University of Foreign Studies. Available online: http://builder.hufs.ac.kr/user/ibas/No31/15.pdf [Accessed 20 August 2014].

Díaz Cintas, J. (2003). 'Audiovisual translation in the third millenium', in Anderman, G. \& Rogers, M. (eds.), Translation Today: Trends and Perspectives, Clevedon: Multilingual Matters Ltd, pp. 192-204.

Díaz Cintas, J. (2009). 'Introduction - Audiovisual translation: An overview of its potential', Díaz Cintas, J. (ed.), New Trends in Audiovisual Translation, Bristol: Multilingual Matters, pp. 112.

Fois, E. (2012). 'Audiovisual translation: Theory and practice'. Between 2/4, pp. 1-16.

Gottlieb, H. (2001). 'Subtitling: visualizing filmic dialogue', in Garcia, L. \& Pereira Rodríguez, A. M. (eds.), Traducción subordinada (II). El subtitulado, Vigo: Servicio de la Universidad de Vigo, pp. 85-110.

Klaudy, K. (1999). Bevezetés a forditás gyakorlatába. Budapest: Scholastica.

Linde, Z. de \& Kay, N. (1999). The Semiotics of Subtitling. Manchester: St. Jerome.

Luyken, G-M. et al. (1991). Overcoming Language Barriers in Television: Dubbing and Subtitling for the European Audience. Manchester: European Institute for the Media.

Martínez-Sierra, J. J. (2009). 'Translating audiovisual humour. A case study'. Perspectives: Studies in Translatology 13/4, pp. 289-296.

Zolczer, P. (2014). 'The constraints of translating humor in audiovisual media', in Zolczer, P. et al. (guest eds.), Eruditio-Educatio, special issue Humour in Contemporary Societies 3/9, pp. 106116. 